Tropical Journal of Pharmaceutical Research November 2015; 14 (11): 1983-1990

ISSN: $1596-5996$ (print); 1596-9827 (electronic)

(C) Pharmacotherapy Group, Faculty of Pharmacy, University of Benin, Benin City, 300001 Nigeria.

All rights reserved.

Available online at http://www.tjpr.org

Original Research Article

http://dx.doi.org/10.4314/tjpr.v14i11.5

\title{
Alpha-Glucosidase Inhibitory and Antioxidant Activity of Solvent Extracts and Fractions of Typha domingensis (Typhaceae) Fruit
}

\author{
Tsun-Thai Chai ${ }^{1,2 \star}$, Mei-Jee Chiam ${ }^{2}$, Chi-Hou Lau ${ }^{2}$, Nor Ismaliza Mohd Ismail ${ }^{1,3}$, \\ Hean-Chooi Ong ${ }^{4}$, Fazilah Abd Manan ${ }^{5}$ and Fai-Chu Wong ${ }^{1,2}$ \\ ${ }^{1}$ Center for Biodiversity Research, ${ }^{2}$ Department of Chemical Science, ${ }^{3}$ Department of Biological Science, Faculty of Science, \\ Universiti Tunku Abdul Rahman, 31900 Kampar, ${ }^{4}$ Institute of Biological Sciences, Faculty of Science, University of Malaya, \\ 50603 Kuala Lumpur, ${ }^{5}$ Department of Biosciences and Health Sciences, Faculty of Biosciences and Medical Engineering, \\ Universiti Teknologi Malaysia, 81310 UTM Johor Bahru, Malaysia
}

*For correspondence: Email: chaitt@utar.edu.my; Tel: +605-468 8888 ext 4516

Received: 19 May 2015

Revised accepted: 10 October 2015

\begin{abstract}
Purpose: To identify a solvent fraction with potent antiglucosidase and antioxidant activities from the fruit of Typha domingensis.

Methods: Extracts were prepared using hexane, chloroform, ethyl acetate, acetone (AE), methanol, and water. Antiglucosidase and 1,1-diphenyl-2-picrylhydrazyl (DPPH) radical scavenging activities of extracts were assessed. The most active extract was partitioned into chloroform, ethyl acetate, butanol (BF) and water, and the antiglucosidase and radical scavenging activities of the fractions were determined. Mode of inhibition of the strongest antiglucosidase fraction was investigated. Polyphenol, coumarin, proanthocyanidin (TPro), and hydroxycinnamic acid contents of the extracts and fractions were evaluated.

Results: $A E$ had the highest antiglucosidase $\left(E C_{50}=12.36 \mu \mathrm{g} / \mathrm{mL}\right)$ and radical scavenging $\left(E C_{50}=8.57\right.$ $\mu \mathrm{g} / \mathrm{mL}$ ) activities. Solvent-partitioning of $A E$ resulted in $B F$, which showed markedly stronger antiglucosidase activity $\left(E C_{50}=4.27 \mu \mathrm{g} / \mathrm{mL}\right)$ than quercetin $\left(E C_{50}=22.18 \mu \mathrm{g} / \mathrm{mL}\right)$. BF also had potent radical scavenging activity $\left(E C_{50}=7.20 \mu \mathrm{g} / \mathrm{mL}\right)$. BF was rich in TPro $(735.65 \mathrm{mg} / \mathrm{g})$ and was a competitive glucosidase inhibitor. TPro content correlated with antiglucosidase $\left(R^{2}=0.709\right)$ and DPPH scavenging activities $\left(R^{2}=0.838\right)$.

Conclusion: TPro-rich BF of $T$. domingensis fruit is a highly potent glucosidase inhibitor and radical scavenger. The findings demonstrate a potential for the development of natural antihyperglycemic agents with antioxidant effect from $T$. domingensis fruit.
\end{abstract}

Keywords: Typha domingensis, Antiglucosidase, Antioxidant, Proanthocyanidin, Hydroxycinnamic acid, Polyphenol, Coumarin

Tropical Journal of Pharmaceutical Research is indexed by Science Citation Index (SciSearch), Scopus, International Pharmaceutical Abstract, Chemical Abstracts, Embase, Index Copernicus, EBSCO, African Index Medicus, JournalSeek, Journal Citation Reports/Science Edition, Directory of Open Access Journals (DOAJ), African Journal Online, Bioline International, Open-J-Gate and Pharmacy Abstracts

\section{INTRODUCTION}

Type 2 diabetes is a chronic metabolic disorder characterized by hyperglycemia. Postprandial hyperglycemia is also a key risk factor for microvascular and macrovascular complications in patients with type 2 diabetes [1]. Thus, antihyperglycemic agents that target postprandial hyperglycemia are recommended for optimal diabetes management and reduction of diabetesassociated complications [1]. 
a-Glucosidase is well-recognized as a therapeutic target for the modulation of postprandial hyperglycemia. a-Glucosidase inhibitors are used in therapy to delay or inhibit gastrointestinal digestion of oligosaccharides and the subsequent release of glucose. This consequently delays or reduces glucose absorption into the bloodstream following food uptake [2]. Acarbose, miglitol, and voglibose are antiglucosidase drugs that are orally administered for the management of postprandial hyperglycemia. Owing to their undesirable side effects, there is great interest among researchers worldwide to search for alternative glucosidase inhibitors. Minimal side effects and low costs of herbal medicines in the treatment of diabetes have encouraged the search for glucosidase inhibitors of plant origin [2,3].

In this study, we evaluated the potential of medicinal plant Typha domingensis Pers. (Typhaceae) as a source of potent, natural $\alpha$ glucosidase inhibitors. The fruit and inflorescence of several Typha species are traditionally used in the treatment of wounds and bleeding in different regions of the world $[4,5]$. $T$. domingensis fruit is not traditionally used as an antidiabetic remedy. However, our preliminary screening has revealed moderate antiglucosidase and antioxidant activities in the crude water extracts of $T$. domingensis fruit, which were greater in potency compared with the male and female flowers [6]. At present, the antiglucosidase and antioxidant capacities of the $T$. domingensis plant are underexplored in the literature. Searching for concurrent antiglucosidase and antioxidant properties in the T. domingensis fruit has practical significance. Diabetic complications that are associated with postprandial hyperglycemia are known to be caused by the induction of oxidative stress [1]. Hence, dual-function antidiabetic agents with concurrent antiglucosidase and antioxidant properties may provide additional benefits when compared with single-function glucosidase inhibitors.

As an extension to our previous screening work [6], a more detailed investigation was undertaken where bioassay-guided fractionation was performed on $T$. domingensis fruit. The antiglucosidase and radical scavenging activities of $T$. domingensis fruit extracts prepared by using extraction solvents differing in polarity were compared in this study. The most potent extract was further solvent-partitioned into different fractions and their antiglucosidase and radical scavenging activities were established. The contents of bioactive phytochemicals (polyphenols, coumarins, proanthocyanidins, and hydroxycinnamic acids) in the solvent extracts and fractions were determined and their correlations with antiglucosidase and radical scavenging activities were analyzed. Enzyme kinetic study was also performed to understand the possible mode of inhibition exerted by the solvent fraction exhibiting the most potent antiglucosidase activity.

\section{EXPERIMENTAL}

\section{Plant sample}

Healthy, mature fruits of Typha domingensis were collected in May 2013 from a population of T. domingensis inhabiting a lakeshore at the Universiti Tunku Abdul Rahman (UTAR) campus. The species of the plant was authenticated by Professor Hean-Chooi Ong, a plant taxonomist at University of Malaya, Malaysia. A herbarium specimen has been stored at UTAR's Faculty of Science for future reference.

\section{Preparation of solvent extracts}

Fruits of $T$. domingensis were cleaned by rinsing in distilled water and then blotted dry with tissue paper. The samples were then oven-dried at 45 ${ }^{\circ} \mathrm{C}$ to constant weight. The dried sample was pulverized using a Waring blender. Solvent extracts were prepared by first mixing the pulverized samples with hexane, chloroform, ethyl acetate, acetone, methanol, or autoclaved deionized water at a 1:10 (dry weight: volume) ratio. Each of the mixtures was incubated at 25 ${ }^{\circ} \mathrm{C}$ for $48 \mathrm{~h}$ on an orbital shaker (100 rpm). The mixtures were subsequently vacuum-filtered and the filtrates were centrifuged at $8600 \mathrm{~g}$ and $4{ }^{\circ} \mathrm{C}$ for $10 \mathrm{~min}$. The supernatants obtained from the hexane extract $(\mathrm{HE})$, chloroform extract $(\mathrm{CE})$, ethyl acetate extract (EAE), acetone extract (AE), methanol extract (ME), and water extract (WE) were collected, whereas the pellets were discarded. The organic solvent extracts were concentrated by rotary evaporation in vacuo and then taken to dryness in an oven at $35^{\circ} \mathrm{C}$; WE was freeze-dried. The solid residues recovered from $\mathrm{HE}, \mathrm{CE}, \mathrm{EAE}, \mathrm{AE}$, and $\mathrm{ME}$ were dissolved in dimethyl sulfoxide (DMSO), whereas the solid residue of WE was redissolved in water. Aliquots of $50 \mathrm{mg} / \mathrm{mL}$ were prepared and stored at $-20{ }^{\circ} \mathrm{C}$ until further use.

\section{Determination of antiglucosidase activity}

Glucosidase inhibitory activity was determined as previously described [6]. Quercetin was used as a reference compound as its effectiveness as a 
glucosidase inhibitor in vivo and in vitro has been established [7,8]. $\quad \mathrm{EC}_{50}$, defined as the extract/fraction concentration required to achieving $50 \%$ antiglucosidase activity, was determined by using linear regression analysis.

\section{Determination of 1, 1-diphenyl-2- picrylhydrazyl (DPPH) radial scavenging activity}

DPPH radical scavenging assay was carried out as previously described [9]. Ascorbic acid was used as the positive control. $E_{50}$, defined as extract/fraction concentration required to achieve $50 \%$ DPPH scavenging activity, was determined by using linear regression analysis.

\section{Antiglucosidase and radical scavenging activities of different fractions}

Fractionation of $A E$ was carried out by suspending the solid residue of $A E(2 \mathrm{~g})$ in 100 $\mathrm{mL}$ of deionized water, followed by sequential partitioning into chloroform, ethyl acetate, and butanol by using a separatory funnel. Chloroform fraction (CF), ethyl acetate fraction (EAF), butanol fraction $(\mathrm{BF})$, and water fraction (WF) were obtained. $\mathrm{CF}, \mathrm{EAF}$, and $\mathrm{BF}$ were concentrated by rotary evaporation in vacuo and then taken to dryness in an oven at $35^{\circ} \mathrm{C}$; WF was freeze-dried. The yield of $\mathrm{CF}, \mathrm{EAF}, \mathrm{BF}$, and WF was 20.2, 20.1, 22.8, and $3.4 \% \mathrm{w} / \mathrm{w}$, respectively. The solid residues recovered from $\mathrm{CF}, \mathrm{EAF}$, and $\mathrm{BF}$ were dissolved in DMSO, whereas the solid residue of WF was redissolved in water. Aliquots of $50 \mathrm{mg} / \mathrm{mL}$ were prepared and stored at $-20{ }^{\circ} \mathrm{C}$ until used. Antiglucosidase and DPPH scavenging activities of fractions were determined as described above. Their $\mathrm{EC}_{50}$ values were also determined by using linear regression analysis.

\section{Phytochemical contents and correlation with bioactivities}

Total phenolic (TP), total proanthocyanidin (TPro), and total hydroxycinnamic acid (THA) contents of extracts/fractions were determined as described in [6]. The three paramerets were expressed as $\mathrm{mg}$ gallic acid equivalents (GAE)/g sample, mg leucocyanidin equivalents (LE)/g sample and $\mathrm{mg}$ caffeic acid equivalents (CAE)/g sample, respectively. Total coumarin (TCou) content was determined as described in [10] and expressed as $\mathrm{mg}$ coumarin equivalents (CE)/g sample. Correlation analyses were carried out between phytochemical contents of all extracts and fractions and the $1 / E_{50}$ values of antiglucosidase and DPPH scavenging activities.
Coefficient of determination $\left(\mathrm{R}^{2}\right)$ was determined from the analyses.

\section{Evaluation of mode of $\alpha$-glucosidase inhibition by butanol fraction}

The antiglucosidase assay described above was carried out in the presence or absence of $\mathrm{BF}$ (4.27 and $5.34 \mu \mathrm{g} / \mathrm{mL}$ ) using $0-2 \mathrm{mM}$ of the $\mathrm{p}-$ nitrophenyl $\alpha$-D-glucopyranoside ( $p$-NPGP) substrate (S). The amount of $p$-nitrophenol formed during the reactions was determined by using a p-nitrophenol standard curve. Reaction velocity ( $v$ ) was calculated as the amount of $p$ nitrophenol formed $(\mathrm{mM})$ per reaction duration (min). A Lineweaver-Burk plot was prepared. The mode of inhibition of glucosidase by $\mathrm{BF}$ was determined by analyzing the double reciprocal $(1 / \mathrm{v}$ versus $1 /[\mathrm{S}])$ plot using the MichaelisMenten kinetics. $V_{\max }$ (maximum velocity) and $k_{m}$ (substrate concentration that yields a halfmaximal velocity) were determined from the plot.

\section{Data analysis}

All experiments were carried out in triplicates and data are expressed as mean \pm standard error of the mean (SEM). Statistical analyses were performed using SAS (Version 9.2). Data were analyzed by one-way ANOVA test and means of significant differences were separated using Fisher's Least Significant Difference (LSD) test or Student's t test at $\alpha=0.05$. Linear regression and correlation analyses were carried out using Microsoft Office Excel 2003.

\section{RESULTS}

All solvent extracts of $T$. domingensis fruit, except HE, exhibited concentration-dependent increases in antiglucosidase activity when tested at $20,40,60,80$, and $100 \mu \mathrm{g} / \mathrm{mL}$ (data not shown). No antiglucosidase activity was detected in HE. The $\mathrm{EC}_{50}$ value of antiglucosidase activity of $\mathrm{AE}(12.36 \mu \mathrm{g} / \mathrm{mL})$ was the lowest among all the solvent extracts (Table 1). The $E_{50}$ values of $\mathrm{AE}$ and $\mathrm{ME}$ are $44 \%$ and $37 \%$ lower than that of quercetin, respectively. The $\mathrm{EC}_{50}$ values of $\mathrm{CE}$ and $\mathrm{EAE}$ are $162 \%$ and $488 \%$ higher than that of quercetin. The $\mathrm{EC}_{50}$ value of WE was not statistically different from that of quercetin.

All six extracts of $T$. domingensis fruit showed an increase in DPPH scavenging activity in a concentration-dependent manner when tested at $20,40,60,80$, and $100 \mu \mathrm{g} / \mathrm{mL}$ (data not shown). 
Table 1: $E_{50}$ values of antiglucosidase and DPPH scavenging activities of solvent extracts

\begin{tabular}{lcc}
\hline \multirow{2}{*}{ Extract } & \multicolumn{2}{c}{$\mathrm{EC}_{50}$ value $(\mu \mathrm{g} / \mathbf{m L})$} \\
\cline { 2 - 3 } HE & Antiglucosidase activity & DPPH scavenging activity \\
CE & nd & $929.30 \pm 22.29^{*}$ \\
EAE & $58.15 \pm 4.46^{\star}$ & $63.98 \pm 0.79^{*}$ \\
AE & $130.33 \pm 0.69^{\star}$ & $43.84 \pm 0.35^{\star}$ \\
ME & $12.36 \pm 0.05^{\star}$ & $8.57 \pm 0.20^{\star}$ \\
WE & $14.03 \pm 0.55^{\star}$ & $11.64 \pm 0.42^{\star}$ \\
Positive control & $24.11 \pm 0.68$ & $11.77 \pm 0.18^{\star}$ \\
& $22.18 \pm 0.88$ & $3.56 \pm 0.12$ \\
& (Quercetin) & (Ascorbic acid)
\end{tabular}

Data are mean \pm SEM $(n=3)$. The asterisks $\left({ }^{*}\right)$ denote values that are significantly different $(p<0.05)$ compared with the positive control, as determined by using Student's $t$ test. nd = not determined. HE had no detectable antiglucosidase activity; hence, $E C_{50}$ value was not calculated

$\mathrm{AE}$ had the lowest $\mathrm{EC}_{50}$ value for $\mathrm{DPPH}$ scavenging activity $(8.57 \mu \mathrm{g} / \mathrm{mL})$ among all the solvent extracts (Table 1). The $\mathrm{EC}_{50}$ value of $\mathrm{AE}$ was 2.4-fold greater than that of ascorbic acid. $\mathrm{HE}$ had the highest $\mathrm{EC}_{50}$ value among the extracts, which is also 260 -fold higher than that of ascorbic acid.

Phytochemical analysis revealed that $A E, M E$, and WE generally contained higher levels of TP, TCou, TPro, and THA contents, relative to HE, $\mathrm{CE}$, and $\mathrm{EAE}$ (Table 2). The four classes of phytochemicals were detected in all six solvent extracts, with the exception that THA was not detectable in HE. Among the six extracts, ME had the highest TCou, TPro, and THA contents, whereas $\mathrm{AE}$ had the highest TP content.

Among the organic and water fractions partitioned from $A E$, concentration-dependent increase in antiglucosidase activity was detected when BF, EAF, and WF were tested at 2, 4, 6, 8, 10, 15 and $20 \mu \mathrm{g} / \mathrm{mL}$ (data not shown). $E_{50}$ values of the antiglucosidase activity of organic and water fractions of $\mathrm{AE}$ ranged between 4.27 and $28.68 \mu \mathrm{g} / \mathrm{mL}$ (Table 3). BF had the lowest $\mathrm{EC}_{50}$ value, which is about 5-fold lower than the $\mathrm{EC}_{50}$ value of quercetin.

Table 2: Phytochemical contents of organic solvent and aqueous extracts

\begin{tabular}{|c|c|c|c|c|}
\hline \multirow{2}{*}{ Extract } & \multicolumn{4}{|c|}{ Phytochemical content } \\
\hline & $T P$ (mg GAE/g) & TCou (mg CE/g) & TPro (mg LE/g) & THA (mg CAE/g) \\
\hline $\mathrm{HE}$ & $2.38 \pm 0.04^{a}$ & $14.37 \pm 0.50^{\mathrm{a}}$ & $0.14 \pm 0.03^{\mathrm{a}}$ & nd \\
\hline CE & $14.01 \pm 0.44^{\mathrm{b}}$ & $33.07 \pm 0.70^{b}$ & $0.80 \pm 0.06^{a}$ & $4.13 \pm 0.18^{a}$ \\
\hline EAE & $61.24 \pm 0.29^{c}$ & $26.05 \pm 0.47^{c}$ & $50.40 \pm 2.67^{b}$ & $50.81 \pm 0.52^{b}$ \\
\hline $\mathrm{AE}$ & $574.07 \pm 7.80^{d}$ & $75.04 \pm 1.97^{d}$ & $298.96 \pm 23.06^{c}$ & $291.85 \pm 7.07^{\mathrm{C}}$ \\
\hline ME & $401.46 \pm 5.77^{e}$ & $92.00 \pm 2.94^{e}$ & $416.87 \pm 11.79^{d}$ & $306.67 \pm 6.42^{d}$ \\
\hline WE & $192.79 \pm 5.10^{\dagger}$ & $41.55 \pm 0.19^{\dagger}$ & $332.35 \pm 16.91^{c}$ & $266.67 \pm 1.28^{\mathrm{e}}$ \\
\hline
\end{tabular}

Data are mean \pm SEM $(n=3)$. Values in the same column that are followed by different superscript letters are significantly different $(p<0.05)$, as determined by using Fisher's $L S D$ test. $n d=$ not detectable

Table 3: $\mathrm{EC}_{50}$ values of the antiglucosidase and DPPH scavenging activities of the solvent fractions of $\mathrm{AE}$

\begin{tabular}{lcc}
\hline & \multicolumn{2}{c}{$\mathrm{EC}_{50}$ value $(\mu \mathrm{g} / \mathbf{m L})$} \\
\cline { 2 - 3 } Fraction & Antiglucosidase activity & DPPH scavenging activity \\
\hline CF & nd & $309.95 \pm 53.49^{*}$ \\
EAF & $27.72 \pm 2.68$ & $7.33 \pm 0.46^{*}$ \\
BF & $4.27 \pm 0.03^{*}$ & $7.20 \pm 0.42^{*}$ \\
WF & $28.68 \pm 2.01^{*}$ & $90.85 \pm 6.65^{\star}$ \\
Positive control & $22.18 \pm 0.88$ & $3.56 \pm 0.12$ \\
& (Quercetin) & (Ascorbic acid) \\
\hline
\end{tabular}

Data are mean \pm SEM $(n=3)$. The asterisks $\left(^{*}\right)$ denote values that are significantly different $(p<0.05)$ compared with the positive control, as determined by using Student's $t$ test. nd = not determined. Chloroform fraction showed an erratic trend in antiglucosidase activity; hence, $E C_{50}$ value was not calculated 
Table 4: Phytochemical contents of the solvent fractions of $A E$

\begin{tabular}{lcccc}
\hline \multirow{2}{*}{ Fraction } & \multicolumn{4}{c}{ Phytochemical content } \\
\cline { 2 - 5 } & $\begin{array}{c}\boldsymbol{T P} \\
(\boldsymbol{m} \boldsymbol{g} \mathbf{G A E} / \boldsymbol{g})\end{array}$ & $\begin{array}{c}\text { TCou } \\
(\boldsymbol{m g ~ C E} / \boldsymbol{g})\end{array}$ & $\begin{array}{c}\text { TPro } \\
(\boldsymbol{m g} \mathbf{g} / \boldsymbol{g})\end{array}$ & $\begin{array}{c}\text { THA } \\
(\boldsymbol{m} \boldsymbol{g} \text { CAE/g) }\end{array}$ \\
\hline CF & $27.16 \pm 3.57^{\mathrm{a}}$ & $49.84 \pm 2.55^{\mathrm{a}}$ & $1.11 \pm 0.25^{\mathrm{a}}$ & $10.49 \pm 0.04^{\mathrm{a}}$ \\
EAF & $844.20 \pm 26.47^{\mathrm{b}}$ & $25.42 \pm 0.31^{\mathrm{b}}$ & $418.43 \pm 8.20^{\mathrm{b}}$ & $549.63 \pm 7.41^{\mathrm{b}}$ \\
BF & $640.96 \pm 11.06^{\mathrm{c}}$ & $36.60 \pm 0.13^{\mathrm{c}}$ & $735.65 \pm 43.63^{\mathrm{c}}$ & $554.81 \pm 1.96^{\mathrm{b}}$ \\
WF & $165.67 \pm 0.78^{\mathrm{d}}$ & $6.72 \pm 0.22^{\mathrm{d}}$ & $2.19 \pm 0.24^{\mathrm{a}}$ & $159.48 \pm 0.93^{\mathrm{C}}$ \\
\hline
\end{tabular}

Data are mean \pm SEM $(n=3)$. Values in the same column that are followed by different superscript letters are significantly different $(p<0.05)$, as determined by using Fisher's LSD test

When evaluated at $4,8,12,16$ and $20 \mu \mathrm{g} / \mathrm{mL}$, a concentration-dependent increase in DPPH scavenging activity was observed among the fractions of $A E$, particularly in $B F, E A F$, and $W F$ (data not shown). $\mathrm{EC}_{50}$ values of the DPPH scavenging activity of organic and water fractions of $A E$ ranged between 7.20 and $309.95 \mu \mathrm{g} / \mathrm{mL}$ (Table 3). Among the fractions, BF had the lowest $\mathrm{EC}_{50}$ value, which is about 2-fold greater than the $\mathrm{EC}_{50}$ value of ascorbic acid. CF had the highest $\mathrm{EC}_{50}$ value among the fractions, which is also 87-fold higher than that of ascorbic acid.

Different levels of TP, TCou, TPro, and THA contents were detected in the organic and water fractions of $A E$ (Table 4). Overall, $E A F$ and $B F$ had the highest TP, TPro, and THA contents, whereas CF had the lowest. CF, nevertheless, had the highest TCou content. EAF had the highest TP content, which is 31 -fold greater compared with CF. BF had the highest TPro content, which is 663-fold greater compared with CF. Notably, on the basis of leucocyanidin equivalents, BF contained about $74 \%$ proanthocyanidins by weight. Both BF and EAF contained the highest and similar levels of THA content, which is about 53-fold higher compared with CF.

Correlation analyses of all extracts and fractions found $1 / E_{50}$ values of antiglucosidase activity to be correlated significantly $(p<0.05)$ with only TPro and THA contents, with $\mathrm{R}^{2}$ of 0.709 and 0.476 , respectively. $1 / \mathrm{EC}_{50}$ values of $\mathrm{DPPH}$ scavenging activity correlated significantly $(p<$ 0.05 ) with TP, TPro, and THA contents, with $R^{2}$ of $0.864,0.838$, and 0.883 , respectively. TPro content is the phytochemical parameter that simultaneously correlated with both antiglucosidase and DPPH scavenging activities at high $R^{2}$ values $(>0.70)$.

In order to determine the mode of inhibition of glucosidase by BF, a Lineweaver-Burk plot was prepared (figure not shown). The plot indicates that the inhibition of glucosidase by BF followed that of competitive kinetics. An increase in $k_{m}$ and unaltered $V_{\max }$ values were detected when glucosidase-catalyzed cleavage of p-NPGP occurred in the presence of BF (Table 5).

Table 5: $k_{m}$ and $v_{\max }$ values for glucosidase activity in the presence or absence of BF

\begin{tabular}{lcc}
\hline Sample & $\mathbf{k}_{\mathbf{m}}(\mathbf{m M})$ & $\mathbf{v}_{\max }(\mathbf{m M} / \mathbf{m i n})$ \\
\hline Control & $1.93 \pm 0.13^{\mathrm{a}}$ & $0.046 \pm 0.005^{\mathrm{a}}$ \\
$4.27 \mu \mathrm{g} / \mathrm{mL} B F$ & $2.61 \pm 0.12^{\mathrm{b}}$ & $0.044 \pm 0.005^{\mathrm{a}}$ \\
$5.34 \mu \mathrm{g} / \mathrm{mL} \mathrm{BF}$ & $3.91 \pm 0.17^{\mathrm{c}}$ & $0.037 \pm 0.007^{\mathrm{a}}$ \\
\hline
\end{tabular}

Data are mean \pm SEM $(n=3)$. Values in the same column that are followed by different superscript letters are significantly different $(p<0.05)$, as determined by using Fisher's LSD test

\section{DISCUSSION}

Our results indicate that the active constituents of $T$. domingensis fruit which exhibited antiglucosidase and radical scavenging activities are likely to be relatively polar in nature. AE, ME, and WE had higher antiglucosidase and DPPH scavenging activities compared with extracts prepared with less polar solvents, such as HE and $\mathrm{CE}$. The three extracts also had higher phytochemical contents relative to extracts prepared with the other solvents. When fractions of $\mathrm{AE}$ were compared, BF and EAF had higher antiglucosidase and DPPH scavenging activities than CF. With the exception of TCou, the phytochemical contents of BF and EAF were also higher compared with that partitioned into CF. Collectively, these results suggest that polar solvents were effective for extracting glucosidase inhibitors and radical scavengers from $T$. domingensis fruit.

Similar to our findings, polar solvent ethyl acetate was more effective in extracting antiglucosidase agents from Callistephus chinensis in comparison with hexane and chloroform [11]. By contrast, chloroform extract of Psoralea corylifolia was a more potent $\alpha$-glucosidase inhibitor than extracts prepared with $50 \%$ ethanol, ethanol, methanol, and water [12]. Our 
observations, together with the aforementioned findings, suggest that optimal solvent polarity for the extraction of antiglucosidase agents from plant samples may not be easily predicted and is likely to be species or sample-dependent.

We found DPPH scavenging activity to be correlated with TP, THA and TPro contents to similar degrees. This concurs with previous reports of correlations between DPPH scavenging activity and TP and THA contents in other plants [13-15]. Positive correlations between DPPH scavenging activity and TPro were also reported for rhizome extracts of highland ferns [14]. When previously screening hot water extracts of $T$. domingensis fruit and flowers for antiglucosidase and antioxidant activity, we found the highest activities in the fruit extract, which also had the highest TPro content [6]. In this study, the antiglucosidase activity of $T$. domingensis fruit extracts and fractions correlated more strongly with TPro content and weakly with THA content. Likewise, in highland ferns, THA content was either less strongly or not correlated to antiglucosidase activity when compared with TPro content [14]. Taking into account our current results and reported evidence in the literature, TPro of $T$. domingensis fruit is a promising source of both glucosidase inhibitors and radical scavengers. On the other hand, THA of $T$. domingensis fruit is likely an important contributor of radical scavenging activity only.

Among all extracts and fractions analyzed, BF stood out as a dual-function antiglucosidase and radical scavenging agent of high potency. BF was a stronger inhibitor of $\alpha$-glucosidase when compared with quercetin. In addition, based on the comparison of $E_{50}$ values, the potency of $\mathrm{BF}$ as a radical scavenger was in the same order of magnitude as that of ascorbic acid. BF had the highest TPro content among all extracts and fractions analyzed. Thus, TPro is likely responsible for the potent dual bioactivities in the TPro-rich BF. Our findings corroborate with the reports of concurrent antiglucosidase and antioxidant activities in proanthocyanidins isolated from black chokeberry [16] and persimmon peel [17].

Our enzyme kinetic study suggests that TPro-rich BF contained active constituents that were possibly able to bind to the catalytic site of $\alpha$ glucosidase, thus acting as competitive inhibitors. Acetone extract of the leaves of Picralima nitida was also reported to be a competitive inhibitor of a-glucosidase [18], although there are more reports of plant extracts and natural products as non-competitive $[19,20]$ and mixed-type [21] a-glucosidase inhibitors. Our study revealed that BF differs in its mode of inhibition from quercetin, which exerts either noncompetitive [22] or mixed-type [23,24] inhibition on a-glucosidase. Notably, the mode of glucosidase inhibition by $\mathrm{BF}$ is the same as that of acarbose, miglitol, and voglibose, three oral antihyperglycemic drugs [25]. An advantage of competitive inhibitors is that their inhibitory action is reversible, thus allowing undesirable effects to be readily mitigated by decreasing the dosage of inhibitors used [26].

In this study, we used yeast $\alpha$-glucosidase for the evaluation of antiglucosidase activity. Yeast a-glucosidase is available in pure form from commercial sources and has been widely used as a model for investigating antiglucosidase properties of natural products. In grape skin and pomace extracts, inhibition against yeast $\alpha$ glucosidase correlated with inhibition against mammalian $\alpha$-glucosidase and suppression of postprandial hyperglycemia in Streptozocininduced diabetic mice [27]. To assess the radical scavenging activity of $T$. domingensis fruit extracts and fractions, we have used the DPPH radical scavenging assay. The assay is widely used for antioxidant screening since it is rapid and simple, using DPPH radicals which are stable and commercially available. However, DPPH radicals have very little similarity to the highly reactive and transient oxygen radicals, such as hydroxyl, peroxyl and superoxide anion radicals, which occur in biological systems [28]. Thus the ability of the $T$. domingensis extracts and fractions to scavenge biologically relevant radicals should be investigated.

\section{CONCLUSION}

In this study, we found that $T$. domingensis fruit is rich in polar bioactive constituents, as evidenced by the high phytochemical contents and strong bioactivities of extracts prepared with polar solvents. Correlation analysis suggests that proanthocyanidins of $T$. domingensis fruit are a promising source of both antiglucosidase inhibitors and radical scavengers. Proanthocyanidins-rich butanol fraction of acetone extract showed more potent antiglucosidase activity than quercetin and strong radical scavenging activity comparable to that of ascorbic acid. The results provide a strong rationale for future exploration of $T$. domingensis fruit as a novel source of antihyperglycemic agent with concurrent antioxidant activity.

Trop J Pharm Res, November 2015; 14(11): 1988 


\section{ACKNOWLEDGEMENT}

This study was supported by UTAR Research Fund which is gratefully acknowledged.

\section{REFERENCES}

1. Aryangat A, Gerich J. Type 2 diabetes: Postprandial hyperglycemia and increased cardiovascular risk. Vasc Health Risk Manag 2010; 6: 145-155.

2. Tundis R, Loizzo MR, Menichini F. Natural products as alpha-amylase and alpha-glucosidase inhibitors and their hypoglycaemic potential in the treatment of diabetes: An update. Mini Rev Med Chem 2010; 10(4): 315-331.

3. Etxeberria U, De La Garza AL, Campin J, Martnez JA, Milagro FI. Antidiabetic effects of natural plant extracts via inhibition of carbohydrate hydrolysis enzymes with emphasis on pancreatic alpha amylase. Expert Opin Ther Targets 2012; 16(3): 269297.

4. Sezik E, Yeşilada E, Tabata M, Honda G, Takaishi Y, Fujita $T$, Tanaka $T$, Takeda $Y$. Traditional medicine in Turkey VIII. Folk medicine in east Anatolia; Erzurum, Erzincan, Agri, Kars, Igdir provinces. Economic Botany 1997; 51(3): 195-211.

5. Zhou J, Xie G, Yan X. Encyclopedia of Traditional Chinese Medicines: Molecular Structures, Pharmacological Activities, Natural Sources and Applications. Vol 5. Berlin, Germany: SpringerVerlag; 2011. $589 p$.

6. Chai T-T, Mohan M, Ong H-C, Wong F-C. Antioxidant, iron-chelating and anti-glucosidase activities of Typha domingensis Pers. (Typhaceae). Trop J Pharm Res 2014; 13(1): 67-72.

7. Jo S, Lee H, Apostolidis E, Jang H, Kwon Y. Comparison of antioxidant potential and rat intestinal alphaglucosidase inhibitory activities of quercetin, rutin, and isoquercetin. Int J Appl Res Nat Prod 2009; 2: 52 $-60$.

8. Kim S, Jo S, Kwon Y, Hwang J. Effects of onion (Allium cepa L.) extract administration on intestinal alphaglucosidases activities and spikes in postprandial blood glucose levels in SD rats model. Int $\mathrm{J} \mathrm{Mol} \mathrm{Sci}$ 2011; 12: 3757-3769.

9. Chai $T-T$, Wong F-C. Whole-plant profiling of total phenolic and flavonoid contents, antioxidant capacity and nitric oxide scavenging capacity of Turnera subulata. J Med Plants Res 2012; 6(9): 1730-1735.

10. Amorim E, Castro V, Melo J, Corrêa A, Peixoto Sobrinho TJS (2012) Standard operating procedures (SOP) for the spectrophotometric determination of phenolic compounds contained in plant samples. Latest Research into Quality Control, ed Akyar I (InTech, Rijeka, Croatia), pp 47-66.

11. Zhang X, Liu Z, Bi X, Liu J, Li W, Zhao Y. Flavonoids and its derivatives from Callistephus chinensis flowers and their inhibitory activities against $\alpha$-glucosidase. EXCLI J 2013; 12: 956-966.

12. Oh KY, Lee JH, Curtis-Long MJ, Cho JK, Kim JY, Lee WS, Park KH. Glycosidase inhibitory phenolic compounds from the seed of Psoralea corylifolia. Food Chem 2010; 121(4): 940-945.

13. Vladimir-Knežević $S$, Blažeković B, Bival Štefan $M$, Alegro A, Köszegi T, Petrik J. Antioxidant activities and polyphenolic contents of three selected Micromeria species from Croatia. Molecules 2011; 16(2): 1454-1470

14. Chai T-T, Elamparuthi S, Yong A-L, Quah $Y$, Ong $H-C$, Wong F-C. Antibacterial, anti-glucosidase, and antioxidant activities of selected highland ferns of Malaysia. Bot Stud 2013; 54(1): 55.

15. Chai T-T, Panirchellvum E, Ong H-C, Wong F-C. Phenolic contents and antioxidant properties of Stenochlaena palustris, an edible medicinal fern. Bot Stud 2012; 53(4): 439-446.

16. Bräunlich $M$, Slimestad $R$, Wangensteen $H$, Brede $C$, Malterud $K$, Barsett $H$. Extracts, anthocyanins and procyanidins from Aronia melanocarpa as radical scavengers and enzyme inhibitors. Nutrients 2013; 5(3): 663-678

17. Lee YA, Eun JC, Tanaka T, Yokozawa T. Inhibitory activities of proanthocyanidins from persimmon against oxidative stress and digestive enzymes related to diabetes. J Nutr Sci Vitaminol 2007; 53(3): 287-292.

18. Kazeem MI, Ogunbiyi JV, Ashafa AO. In vitro studies on the inhibition of $\alpha$-amylase and $\alpha$-glucosidase by leaf extracts of Picralima nitida (Stapf). Trop J Pharm Res 2013; 12(5): 719-725.

19. Liu X, Luo J, Kong L. Phenylethyl cinnamides as potential $\alpha$-glucosidase inhibitors from the roots of Solanum melongena. Nat Prod Commun 2011; 6(6): 851-853.

20. Ha TJ, Lee JH, Lee MH, Lee BW, Kwon HS, Park CH, Shim KB, Kim HT, Baek IY, Jang DS. Isolation and identification of phenolic compounds from the seeds of Perilla frutescens (L.) and their inhibitory activities against $\alpha$-glucosidase and aldose reductase. Food Chem 2012; 135(3): 1397-1403.

21. Escandón-Rivera S, González-Andrade $M$, Bye $R$, Linares E, Navarrete A, Mata R. a-Glucosidase inhibitors from Brickellia cavanillesii. J Nat Prod 2012; 75(5): 968-974.

22. Lee DS, Jong GK, Lee SH. Inhibition of a-glucosidase activity by quercetin. Korean J Microbiol Biotech 2006; 34(4): 368-372.

23. Tadera K, Minami Y, Takamatsu K, Matsuoka $T$. Inhibition of $\alpha$-glucosidase and $\alpha$-amylase by flavonoids. J Nutr Sci Vitaminol 2006; 52(2): 149-153.

24. Li YQ, Zhou FC, Gao F, Bian JS, Shan F. Comparative evaluation of quercetin, isoquercetin and rutin as inhibitors of a-glucosidase. J Agric Food Chem 2009; 57(24): 11463-11468. 
25. Derosa G, Maffioli P. $\alpha$-Glucosidase inhibitors and their use in clinical practice. Arch Med Sci 2012; 8(5): 899906.

26. Brindis F, González-Trujano ME, González-Andrade M, Aguirre-Hernández E, Villalobos-Molina R. Aqueous extract of Annona macroprophyllata: A potential $\alpha$ glucosidase inhibitor. BioMed Res Int 2013; 2013: 6.
27. Zhang L, Hogan S, Li J, Sun S, Canning C, Zheng SJ, Zhou K. Grape skin extract inhibits mammalian intestinal $\alpha$-glucosidase activity and suppresses postprandial glycemic response in streptozocintreated mice. Food Chem 2011; 126(2): 466-471.

28. Karadag A, Ozcelik B, Saner S. Review of methods to determine antioxidant capacities. Food Anal Method 2009; 2(1): 41-60. 